\section{FIREBALLS VISIBLE IN THE SPRING MONTHS.}

THOUGH ordinary shooting stars are rare in the second quarter of the year, fireballs appear to be moderately numerous and to afford definite evidence of some interesting systems which, like the comets of short period, move in direct orbits with small inclinations. Many of these systems remain uncertain, and necessarily so from the circumstances, for fireballs are usually seen accidentally, and often only by persons who are unable to record them accurately. But every year fortunately adds something to our knowledge of these interesting and brilliant visitors. They are occasionally witnessed and described by practised observers, their real paths computed, and the accumulated data now enables us to discover the special periods when fireballs are usually abundant and to determine the positions of some of their principal radiant points.

I have just completed a comparison of the dates of more than too fireballs (the majority of which appeared over England) seen during the last ten years in the spring quarter, and find the more prolific epochs to have been as under :-

April I-5, 3-12, and I9-22: May 2-6, II--I6, 24--28; and June 8-ro.

A discussion of many hundreds of fireballs observed before I89o, which I undertook some years ago, indicated also the dates May 3I, June 6-7 and 28-30. The June 6-7 epoch nearly corresponds with the more recent one of June 8-10, the absence of leap year in $x 900$ and other causes having probably made the date of occurrence a little later.

Observations this year at the following epochs will be likely to add to our knowledge of these striking objects, and it is hoped they will be specially looked for during the earlier part of the night, for fireballs are more numerous during the two or three hours after sunset than at later times:-

\begin{tabular}{|c|c|c|}
\hline $\begin{array}{l}\text { Fireba } \\
\text { April }\end{array}$ & $\begin{array}{l}1 \text { Epoch } \\
19-22\end{array}$ & Notes \\
\hline April & $19-22$ & Lyrid epoch. There will be slight moonlig \\
\hline $\begin{array}{l}\text { May } \\
\text { May }\end{array}$ & $2-6$. & Aquarid epoch. Partial moonlight. \\
\hline May & $\begin{array}{l}11-10 . \\
24-28\end{array}$ & $\begin{array}{l}\text { Moon invisible. } \\
\text { Bright moonlight. }\end{array}$ \\
\hline May & $3 \mathrm{I}$. & \\
\hline $\begin{array}{l}\text { June } \\
\text { June }\end{array}$ & $\begin{array}{l}6-7 \\
8-1\end{array}$ & No moonlight in evenings. \\
\hline June & $28-30$. & Bright moonlight. \\
\hline
\end{tabular}

The fact of there being bright moonlight at several of these epochs need not interfere with observation. Fireballs are sometimes so vividly luminous as apparently "to put the moon into the shade." I have occasionally seen them flash out with astonishing brilliancy and cause shadows, though the nearly full moon was shining at the time!

In April many fine meteors diverge from Virgo and Libra, while in May there are Serpentids, Scorpiids and Ophiuchids. In June the chief radiant is in Scorpio. As a rule, fireballs move very slowly in long flights directed from radiants not far above the horizon. Whenever such objects are seen their paths amongst the stars should be carefully recorded and their durations of flight estimated.

\section{W. F. Denning.}

\section{SEISMOLOGICAL NOTES.}

THE periodicity of the aftershocks of the great Indian eurthquake of June 12, 1897, is treated by Mr. R. D. Oldham in vol. xxxv. of the Memoirs of the Geological Survey of India. The principal conclusions, drawn from the records of the Shillong seismograph, have already been published in the Journal of the Asiatic Society of Bengal, vol. xxxi., and the present paper contains particulars of the dis cussion of other records, of varying completeness, and shows that they confirm the conclusion already arrived at, that there is a tendency to a slight increase of frequency about the time when the horizontal tide-producing forces are varying. most rapidly in amount and direction. The paper is illustrated by a number of curves of frequency, among which we may specially refer to one showing the semidiurnal frequency of shocks during the half days in which the vari- ation of tidal stress is greatest and least; the curves are striking as they stand, but would have been even more instructive had the relative frequency been calculated to the mean of the whole year instead of to that of each period. The very marked diurnal variation in frequency is shown to have no relation to the variations of barometric pressure.

In Die Erdbeben Warte, Nos. 3, 4, 5, iii. Jahrg., 1903-4, Dr. A. Cancani contributes an interesting paper on the frequency of large earthquakes and small changes in latitude. What the author does is to examine critically, to extend, and to confirm results published in the seismological reports of the British Association (see report for I900, p. I07), which show that when world-shaking earthquakes have been frequent pole displacements have been comparatively great and vice versâ. For example, between 1895 and 1902 inclusive, if we write the number of world-disturbing earthquakes in the position of numerators, and the corresponding pole displacements expressed in seconds of arc in the position of denominators, we get the following series:-

$$
\frac{9}{0.53} \quad \frac{18}{0.91} \quad \frac{44 \text { or } 47}{1.07} \quad \frac{30}{0.79} \quad \frac{27}{0.72} \quad \frac{17}{0.32} \quad \frac{22}{0.53} \quad \frac{29}{0.97}
$$

For the first two years the earthquake records, owing to the small number of observing stations, are somewhat uncertain. The results of investigations published in the British Association report in 1903, which show that large earthquakes have also been frequent when the change in the direction of pole displacements was comparatively rapid, Dr. Cancani has apparently not had an opportunity to discuss. Two other papers in the same journal relate to the magnetic storm of October 31, x903. In the latter of these, by Dr. A. Belar, references are made to a possible relationship between such disturbances, earthquakes, sunspots, and other phenomena.

An article on the work accomplished by Alexander von Humbolt in the domain of seismology and vulcanology, a description of the terrible shock which on January 25,1348 , destroyed Villach and shook central Europe, a register from the Laibach Observatory, and a reproduction of registers for May, I903, which are largely those of stations cooperating with the British Association, together with reviews and notices relating to seismology, complete Dr. A. Belar's useful journal.

In No. I9 of the Publications of the Earthquake Commission of Vienna, Dr. E. v. Mojsisovics gives a general account of the earthquakes recorded in 1902 in the Austrian Empire, to which he adds an interesting note relating to records obtained from a pair of Wiechert's seismographs established at Pribram, one of which is on the surface and the other at a depth of $\operatorname{II} 5 \mathrm{~m}$. Both pendulums from time to time show pulsatory movements, but the movements below are less than those on the surface.

In the records of earthquakes with distant origins the details of the seismograms from both instruments exactly agree, with the exception that the amplitude recorded underground is somewhat less than that recorded on the surface, which may mean that one instrument has a smaller sensibility than the other.

No. 20 contains the earthquake register from ReubeurEhlert pendulums at Trieste, whilst No. $2 x$ gives similar records from Kremsmünster, both catalogues referring to 1902.

In No. 6, vol. iv., of the Bollettino della Società sismologica Italiana, earthquake registers are brought up to the end of June, 1902. In the latest register issued by Strassburg, which refers to June, I903, we find the duration of the earthquakes recorded at Strassburg and the time of their commencement. In addition we find the "commeucements "for teleseisms as recorded at various stations round the world, which for the most part are reproduced from the registers issued by the British Association. In the Laibach registers there are similar but more complete reproductions. The most complete reproductions, containing not only the times of commencement, but also times of certain phases of motion, duration, and amplitude, are those in the Bollettino. A sheet that only gives the times at which earthquakes have commenced has a value, but this would be enormousiy enhanced by adding other details. 